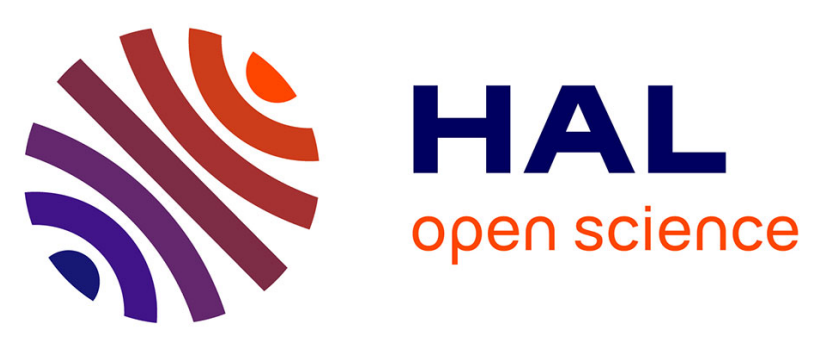

\title{
Synthesis of Acrylic-Polyurethane Hybrid Latexes by Miniemulsion Polymerization and Their Pressure-Sensitive Adhesive Applications
}

Ravindra Udagama, Elise Degrandi-Contraires, Costantino Creton, Christian Graillat, Timothy Mckenna, Elodie Bourgeat-Lami

\section{To cite this version:}

Ravindra Udagama, Elise Degrandi-Contraires, Costantino Creton, Christian Graillat, Timothy Mckenna, et al.. Synthesis of Acrylic-Polyurethane Hybrid Latexes by Miniemulsion Polymerization and Their Pressure-Sensitive Adhesive Applications. Macromolecules, 2011, 44 (8), pp.2632-2642. 10.1021/ma200073d . hal-00723738

\section{HAL Id: hal-00723738 \\ https://hal.science/hal-00723738}

Submitted on 22 Dec 2021

HAL is a multi-disciplinary open access archive for the deposit and dissemination of scientific research documents, whether they are published or not. The documents may come from teaching and research institutions in France or abroad, or from public or private research centers.
L'archive ouverte pluridisciplinaire HAL, est destinée au dépôt et à la diffusion de documents scientifiques de niveau recherche, publiés ou non, émanant des établissements d'enseignement et de recherche français ou étrangers, des laboratoires publics ou privés. 


\section{Synthesis of Acrylic-Polyurethane Hybrid Latexes by Miniemulsion Polymerization and their Pressure-Sensitive Adhesive Applications}

\begin{tabular}{|r|l|}
\hline Journal: & Macromolecules \\
\hline Manuscript ID: & ma-2011-00073d.R1 \\
\hline Manuscript Type: & Article \\
\hline Date Submitted by the & n/a \\
\hline Complete List of Authors: & $\begin{array}{l}\text { Udagama, Ravindra; Université de Lyon, Laboratoire de Chimie, } \\
\text { Catalyse, Polymères et Procédés - LCPP - CNRS } \\
\text { Degrandi, Elise; E.S.P.C.I., Laboratoire PPMD-UMR 7615 } \\
\text { Creton, Costantino; E.S.P.C.I., Laboratoire PPMD-UMR 7615 } \\
\text { Graillat, Christian; Université de Lyon, Laboratoire de Chimie, } \\
\text { Catalyse, Polymères et Procédés - LCPP - CNRS } \\
\text { McKenna, Timothy; Université de Lyon, Laboratoire de Chimie, } \\
\text { Catalyse, Polymères et Procédés - LCPP - CNRS } \\
\text { Bourgeat-Lami, Elodie; Université de Lyon, Laboratoire de Chimie, } \\
\text { Catalyse, Polymères et Procédés - LCPP - CNRS }\end{array}$ \\
\hline & \\
\hline
\end{tabular}

\section{SCHOLARONE ${ }^{\text {M }}$ Manuscripts}




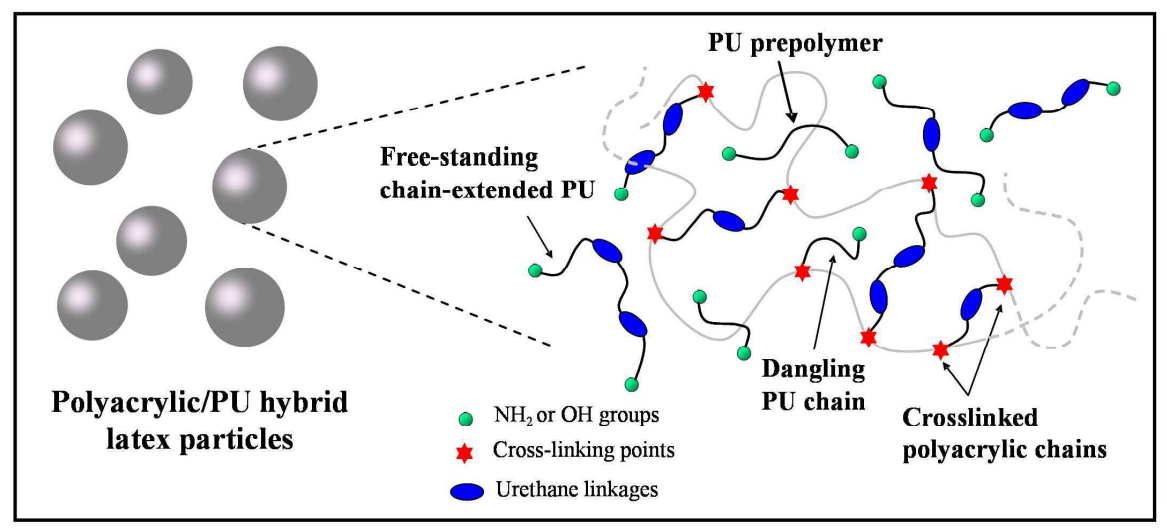

$625 \times 312 \mathrm{~mm}(96 \times 96 \mathrm{DPI})$ 


\section{Synthesis of Acrylic-Polyurethane Hybrid Latexes by Miniemulsion}

Polymerization and their Pressure-Sensitive Adhesive Applications

Ravindra Udagama, ${ }^{1}$ Elise Degrandi-Contraires, ${ }^{2}$ Costantino Creton, ${ }^{2}$ Christian Graillat, ${ }^{1}$ Timothy F.L. McKenna, ${ }^{1}$ Elodie Bourgeat-Lami ${ }^{1 *}$

${ }^{1}$ Université de Lyon, Univ. Lyon 1, CPE Lyon, CNRS UMR 5265, Laboratoire de Chimie, Catalyse, Polymères et Procédés (C2P2), LCPP group, 43 Bd du 11 Novembre 1918, F69616, Villeurbanne, France.

${ }^{2}$ Laboratoire de Physico-Chimie des Polymères et Milieux Dispersés, CNRS-UPMCESPCI Paristech, Paris, France.

* Corresponding author.

Email adress: bourgeat@lcpp.cpe.fr 


\section{Abstract}

The successful incorporation of a NCO-terminated polyurethane (PU) prepolymer in a hybrid miniemulsion is described with the purpose to develop waterborne, high solids, acrylic-PU hybrid nanoparticles to be used in pressure-sensitive-adhesive (PSA) applications. To ensure efficient chemical incorporation of the reactive PU into the hybrid latex particles, the NCO moieties were reacted with 2-hydroxyethyl methacrylate (HEMA). The NCO-HEMA coupling reaction was thoroughly studied by conductimetry in order to control the extent of HEMA incorporation into the PU chains. The resulting HEMA-end capped prepolymers were chain extended in situ with Bisphenol A (BPA) and polymerized with $n$-butyl acrylate, methyl methacrylate and acrylic acid in the presence of small amounts of a chain transfer agent to form PU/acrylic particles. The amount of chain transfer agent, the ratio between HEMA and BPA and the amount of PU were varied step by step to study their influence on the final film properties. The miniemulsions and resulting hybrid latexes were characterized in terms of size, monomer conversion, evolution of the ratio of the number of polymer particles to the number of droplets $\left(\mathrm{N}_{\mathrm{p}} / \mathrm{N}_{\mathrm{d}}\right)$ and gel content. In parallel, the mechanical and adhesive properties of the films were tested using probe tack experiments. This allowed us to identify the reaction conditions making it possible to obtain high solids content PU/acrylic hybrid latexes, usable to prepare waterborne pressure-sensitive-adhesive films with good adhesive properties, using a simple miniemulsion polymerization method. 


\section{Introduction}

Polyurethanes (PUs) are widely used in different applications such as coatings and adhesives due to their superior properties like gloss, chemical resistance, toughness, flexibility and film formation. ${ }^{1-3}$ However, the synthesis of traditional solvent-borne PUs has come into disfavour due to the presence of volatile organic compounds. Therefore, waterborne PU dispersions have received increasing attention in recent years. Aqueous PU dispersions are commonly prepared by the incorporation of ionic groups into the polymer structure to enhance the hydrophilicity of the polymer chains and promote water dispersability. ${ }^{4-7}$ Those PUs that contain ionic groups are called PU ionomers. ${ }^{4}$ Several excellent review articles are available which detail the various chemistries and processes that can be used to manufacture aqueous PU dispersions. ${ }^{8-10}$ However, as the traditional way of preparing waterborne PU dispersions usually involves hydrophilic segments in the PU backbone, the properties of these PU polymers are generally not as good as those of hydrophobic PUs prepared by solvent-based polymerization. ${ }^{11-12}$ Overcoming this limitation is one of the keys to producing high quality aqueous dispersions containing PU.

There is also increasing interest in the elaboration of hybrid materials that combine different polymers because the resulting products most often exhibit superior properties to those of their individual components. ${ }^{13,14}$ Yet, there is clear benefit in combining PUs and acrylic polymers. ${ }^{15-39}$ Although direct blending of a polyurethane dispersion and an aqueous acrylic emulsion is a popular and easy to handle approach, ${ }^{15}$ it results in many cases in films with properties of poor quality because of limited compatibility between PU and polyacrylates. ${ }^{17,20,28,34}$ Therefore, different strategies for dispersing PU resins into acrylic polymers other than by direct blending have been described recently in the literature. For instance, a frequently reported technique consists in polymerizing acrylic monomers in the presence of preformed PU dispersions via seeded emulsion polymerization. ${ }^{15-29}$ However, this strategy most often leads to structured particles in which the PU and the polyacrylic are phase segregated, and is furthermore mainly restricted to hydrophilic PUs. Therefore, in an effort to overcome these limitations and 
create intimate mixing between the two components, acrylic/PU hybrid latexes have been synthesized by miniemulsion polymerization. ${ }^{12,30-39}$

Miniemulsion polymerization is similar to a conventional emulsion polymerization system in the sense that it employs similar monomers, surfactants and initiators to make a dispersion of particles with diameters in the 50-300nm range. ${ }^{40-41}$ The major difference between the two systems is that in miniemulsion, nanosized droplets are formed in water through sonication, ${ }^{42}$ high pressure homogenization ${ }^{43}$ or using static mixers. ${ }^{44,45}$ The miniemulsion droplets are stabilized against coalescence by using an appropriate surfactant (typically the same as in conventional emulsion polymerization) while Ostwald ripening can in principle be controlled with the choice of an appropriate co-stabilizer (or hydrophobe) to minimize the difference of chemical potential between two monomer droplets and thereby retard the molecular diffusion degradation. ${ }^{46}$ Hence, if the system is correctly formulated, the nanodroplets become the prevalent locus of nucleation. This means that if one can directly incorporate a product such as PU in the monomer phase before it is dispersed, it should be possible to create in situ polymer-polymer hybrids by droplet nucleation. In the most desirable scenario, all the monomer droplets should contain PU and the miniemulsion polymerization should ideally lead to a 1:1 copy of droplets to particles (i.e. $\mathrm{N}_{\mathrm{p}} / \mathrm{N}_{\mathrm{d}} \approx 1$ ).

Various reports describe the synthesis of PU/acrylic hybrids by miniemulsion polymerization. ${ }^{30-34}$ In the pioneering work of Gooch et al., ${ }^{30}$ a linseed oil-modified PU prepolymer with alkenyl double bonds was dissolved into acrylic monomers to form hybrid miniemulsion droplets that were subsequently polymerized. The PU resin was employed as both reactant and co-stabilizer and only limited grafting of the acrylic to the PU was observed. In a related approach, Wang and co-workers ${ }^{31}$ studied the kinetics of miniemulsion copolymerization of methyl methacrylate and $n$-butyl acrylate nanodroplets containing varying amounts of PU and showed that PU could also efficiently stabilize the monomer droplets against Ostwald ripening. They further compared the miniemulsion route to a seeded emulsion polymerization technique and showed that miniemulsion resulted in films with better mechanical properties. ${ }^{33,34}$ More recently, Li et al. ${ }^{32}$ described 
the successful elaboration of nanosized PU/poly(n-butyl methacrylate) hybrid latexes using a redox initiator. The compatibility between PU and the polyacrylate was increased by incorporating a vinyl functionality at the end of the PU chains, which was further reacted with acrylic radicals to form graft copolymers. Internal chain extension was used to increase the PU molecular weight and at the same time creating a network by linking the pendant urethane chains together.

A rapid survey of the recent literature shows that most of the PU/acrylic hybrids synthesized until now have been designed for coating applications. To the best of our knowledge, there are very few reports dedicated to the elaboration of adhesive PU/acrylic hybrids and the only one reported focuses on the modification of PU semi-structural adhesives with $20 \%$ of poly $\left(n\right.$-butyl acrylate). ${ }^{26}$

The purpose of this study is to develop an efficient acrylic/PU hybrid system to be used in pressure sensitive adhesive (PSA) applications, ${ }^{47}$ hence a situation where the PU needs to be the minority component to maintain a low enough elastic modulus and where the detailed architecture of the partially crosslinked acrylic polymer needs to be carefully controlled. To this end, a low molecular weight isocyanate-terminated PU (hereafter referred to as reactive PU) was used as prepolymer and the acrylic composition was typical to those used for PSAs. As our main objective was to get efficient chemical incorporation of the reactive PU into the acrylic latex and achieve intimate mixing between the two components, the NCO functions were first reacted with HEMA to incorporate methacrylic groups into PU for further reaction with the acrylic radicals. The chemical reaction between HEMA and PU was performed in a separate step and characterized both quantitatively and qualitatively. Then, the remaining NCO groups were reacted in situ with a hydrophobic chain extender (BPA) to increase PU molecular weight and modify the crosslinking of the acrylic polymer chains. As carefully designing the network architecture is key in achieving high performance acrylic PSAs, ${ }^{48-50}$ we varied successively the amount of chain transfer agent, the ratio of HEMA to BPA and the amount of PU, and studied their influence on the polymerization reaction. In parallel, probe-tack experiments were performed on the films to evaluate their adhesive 
performances and suggest changes to the formulation of hybrid latexes in order to identify the important variables that can be used to systematically improve the final PSA properties. In addition, in order to make commercially useful samples, all of the experiments were run with high solid contents (typically in the $40-50 \%$ range), and low particle sizes with average diameters of the order of $100 \mathrm{~nm}$. This paper focuses on the process and the impact of the synthesis parameters, and a companion paper ${ }^{51}$ is dedicated to the role of these parameters on the molecular architecture and the macroscopic properties of the PU/acrylic hybrid network.

\section{Experimental}

\section{Materials}

n-Butyl acrylate (BA 99+\%, Acros), acrylic acid (AA 99+\%, Acros) and methyl methacrylate (MMA 99+\%, Acros) were used as received. Dowfax-2A1 (45\%, graciously supplied by Dow Chemicals) was used as the anionic surfactant. Reactive PU (Incorez 701 ) of molecular weight of $3285 \mathrm{~g} \cdot \mathrm{mol}^{-1}$ was graciously supplied by Industrial Copolymers Limited, and used as received. Bisphenol A (BPA, analytical grade, Sigma Aldrich), dibutyltin dilaurate (95\%, Sigma Aldrich), 2-hydroxyethyl methacrylate (HEMA 97\%, Sigma Aldrich), diethyl amine (98+\%, Avocado), isopropanol (99+\%, Carlo Erba) and hydrochloric acid ( $\mathrm{HCl} 0.1 \mathrm{~N}$, Acros) were all used as received. 1-Dodecylmercaptan (98.5\%, Acros) was used as chain transfer agent (CTA). Octadecyl acrylate (ODA 97\%, Sigma Aldrich) was used as the co-stabilizer. Potassium persulfate (KPS, Acros) was used as the water soluble initiator. Tertiary butyl hydroperoxide (TBHP diluted at $70 \%$ in water, Acros) and sodium formaldehyde sulfoxylate (SFS, Sigma Aldrich) were used as the redox initiator pair. Tetrahydrofuran (THF, Fischer Scientific) was used as solvent for the selective extraction experiments. Deionised water was used throughout the work.

\section{Emulsion Preparation and Polymerization}

All experiments carried out in this work are based on the recipe shown in Table 1 unless otherwise specified. 
Table 1. Miniemulsion polymerization recipe used in the synthesis of acrylic/reactive PU hybrid latexes. All latexes have a solids content of $49.8 \%$.

\begin{tabular}{lcc}
\hline Raw Materials & Weight $(\mathrm{g})$ & $\begin{array}{c}\text { Active } \\
\text { (wt\% to monomers) }\end{array}$ \\
\hline Water & 120 & $/$ \\
Dowfax 2A1 (45\%) & 4.0 & 2.0 \\
BA & 80.5 & 89.5 \\
MMA & 8.5 & 9.5 \\
AA & 1.0 & 1.0 \\
ODA & 4.5 & 5.15 \\
PU (Incorez 701) & 23.6 & 25.0 \\
HEMA & Variable & $0-1.6$ \\
BPA & Variable & \\
Dibutyltin dilaurate & 0.01 & \\
1-Dodecylmercaptan & Variable & $0-0.4$ \\
TBHP & 0.10 & \\
SFS & 0.26 & \\
\hline
\end{tabular}

${ }^{a}$ Based on the free NCO functions remaining after the reaction with HEMA. Half a stoichiometric amount was used in the reactions from T107 to T153 and a stoichiometric amount was used in the reactions from T159 to T164. ${ }^{\mathrm{b}} 0.005 \mathrm{~g}$ was used for the coupling reaction between HEMA and NCO and $0.005 \mathrm{~g}$ for chain extension with BPA.

A typical procedure for PU incorporation into the hybrid latexes was as follows. A known quantity of PU was dissolved in the monomer mixture (BA/MMA/AA and ODA) as per the recipe of Table 1. Then, a known amount of HEMA and dibutyltin dilaurate was introduced in the reactor (see section 1.2 for more details of the reaction between HEMA and NCO). The reaction was allowed to take place for 12 hours at room temperature under stirring. A calculated amount of BPA was next introduced together with dibutyltin dilaurate and the reaction mixture was stirred for 30 minutes before mixing with the aqueous phase in which the surfactant was previously dissolved. The organic phase was added slowly to the aqueous phase while stirring. The mixture was further stirred for 5 minutes and sonicated in an ice bath for 6 minutes at $80 \%$ of $480 \mathrm{~W}$ output power in continuous mode. These conditions were selected to minimize side reactions of NCO with water. A high Intensity Ultrasonic Processor (Branson, model CV 26) operating at $80 \%$ of the $600 \mathrm{~W}$ maximum power was used to prepare the miniemulsions. The droplet size was measured soon after sonication and then several hours afterward to ensure that the droplets 
are stable for a duration of 4-5h. Thus if any change in droplet size is observed during the reactions, it will not be attributed to an intrinsic lack of stability of the original dispersion. All reactions were carried out at $50^{\circ} \mathrm{C}$ (except those initiated with KPS that were performed at $70^{\circ} \mathrm{C}$ ) in batch using a $200 \mathrm{~mL}$ jacketed glass reactor connected to a heated water bath for temperature control. The reactor was equipped with a glass stirrer (the stirring rate was fixed at $200 \mathrm{rpm}$ ), a reflux condenser, a nitrogen inlet and outlet and a valve on the bottom to remove the latex. Samples were occasionally withdrawn through a valve in the bottom of the reactor for analysis. Conversions were measured by gravimetry. Average droplet $\left(D_{d}\right)$ and particle $\left(D_{p}\right)$ diameters were measured by photon correlation spectroscopy at $90^{\circ}$ (Zetasizer $1000 \mathrm{HS}_{\mathrm{A}}$ from Malvern). At least 5 measurements were performed for each sample. The broadness of the distribution was given by a dimensionless number called polydispersity index (PI) determined from the autocorrelation function using the second-order method of cumulant analysis. Unless otherwise indicated, the PI values were less than 0.2 for all of the droplet and particle sizes measured in this work. This indicates that all of the dispersions can be considered to be monomodal and narrow enough to be characterized by an average diameter. Gel content was determined by selective dissolution of a known amount of a vacuum dried latex sample at $70^{\circ} \mathrm{C}$ for $24 \mathrm{~h}$ in a two necked round flask equipped with a condenser using THF as the solvent. The gel content was determined as follows:

$$
\text { Gel content }(\mathrm{wt} \%)=\left(\mathrm{W}_{2} / \mathrm{W}_{1}\right) \times 100
$$

Where $\mathrm{W}_{2}$ is the weight of the dried polymer after extraction which corresponds to the insoluble part (gel fraction) and $\mathrm{W}_{1}$ is the weight of the dried polymer introduced into the flask.

A CDM 83 conductivity meter (radiometer) was used for conductivity measurements. Molar masses and molar mass distributions of the PU prepolymer were determined by Size Exclusion Chromatography (SEC) using a modular system equipped with an HPLC pump (Waters 515), an automatic sample injection (Waters 717 Plus) and multiple detectors using THF as the eluent. The first column (PLgel $5 \mu \mathrm{m}$ ) was followed by three columns: 2 PLgel $5 \mu \mathrm{m}$ Mixed $\mathrm{C}(300 \times 7.5 \mathrm{~mm})$ and 1 PLgel $5 \mu \mathrm{m} 500 \mathrm{~A}$ 
(300x7.5mm). A Waters 410 refractometer was used for detection and the molar masses were calculated using narrow polydispersity polystyrene standard. Infra Red analyses were carried out using a Nicolet Protégé 460 Fourier Transform Infra Red (FTIR) spectrometer coupled to a personal computer for data output and analysis.

\section{Characterization of reactive $P U$}

Quantitative determination of the amount of NCO groups of PU was performed using a conductimetric titration method as described by Li et al. ${ }^{32}$ Typically, a known amount of PU was dissolved in a known volume of the monomer mixture (BA/MMA 90/10 wt/wt). Then, a known amount of diethyl amine was added to the solution of PU and dibutyltin dilaurate was added to catalyse the reaction between the amine and NCO. The reaction was allowed to take place for various periods of time ranging from a few hours to several days. A known volume of each solution was then back titrated with $\mathrm{HCl}$ dissolved in isopropanol. The amount of NCO functions per gram of PU was calculated from the amount of excess diethyl amine.

\section{Mechanical characterizations}

The adhesive properties were characterized with a laboratory probe-tack test as reported elsewhere. ${ }^{52-53}$ In a typical experiment, a stainless steel probe was contacted with the adhesive layer deposited on a glass slide and removed at a constant velocity of $100 \mu \mathrm{m} . \mathrm{s}^{-1}$ (unless mentioned otherwise) after a contact time and contact pressure of $1 \mathrm{~s}$ and $1 \mathrm{MPa}$, respectively. From the force and displacement data, we could extract the adhesion energy (integral under the force-displacement curve), the maximum deformation of the layer before debonding (distance where the force returns to zero normalized by the initial thickness of the film) and the mode of failure (bulk cohesive or interfacial).

The films for the adhesive tests were prepared by drying during one week a given volume of latex deposited on microscopic glass slides. The glass slides were then placed at $110^{\circ} \mathrm{C}$ for 3 minutes. More details on the tests and the experimental conditions can be found in a companion paper. ${ }^{51}$ 


\section{Results and Discussion}

\section{PU chemical modifications}

\subsection{Quantitative characterization of reactive $P U$}

The amount of NCO groups in the PU prepolymer was determined by the classical diethylamine titration method ${ }^{54}$ as reported elsewhere. ${ }^{32}$ The reaction between isocyanates and primary amines are known to be fast but depends very much on the reactivity of the isocyanate group and on the reaction conditions. Therefore, in order to obtain reliable data, we performed a kinetic study. Figure 1 illustrates the time dependence of the reaction between NCO and diethyl amine under our experimental conditions. When comparing the values of NCO functions per gram of PU, it was found that the value relevant to a shorter reaction time is less by about $20 \times 10^{-5}$ moles than the value relevant to overnight $(12 \mathrm{~h})$ reaction time. After analyzing more conductimetric titration results of solutions which were allowed to react several days, it was found that the value obtained for NCO functions per gram of PU is constant and same as the value obtained for overnight reaction. The amount of NCO functions per gram of PU was therefore established as $61 \times 10^{-5}$ moles. Hence, the molar mass of PU was calculated to be $3279 \mathrm{~g} \cdot \mathrm{mol}^{-1}$ assuming that the PU chains are di-functional (e.g., they have NCO groups on both ends). This value was compared to the number average molar mass determined by SEC (Figure S1, Supporting Information). The molar mass determined by NCO titration is close to the mass relevant to the main peak (e.g., 3720g.mol ${ }^{-1}$ ) but slightly lower than the number average molecular weight (e.g., $4340 \mathrm{~g} \cdot \mathrm{mol}^{-1}$ with a polydispersity index of 1.42). However, SEC analyses are based on polystyrene standards and do not actually give an absolute measure of molar mass which may account for the observed discrepancy between the two methods. The reactive PU was further characterized by FTIR (Figure S2 in the Supporting Information). The spectrum shows all characteristics signals of polyurethane (the peak assignments are reported in the Figure). In addition, no urea band was detected at $1675 \mathrm{~cm}^{-1}$ indicating that the reactive PU did not undergo any undesirable side reaction with water upon storage. ${ }^{55}$ 


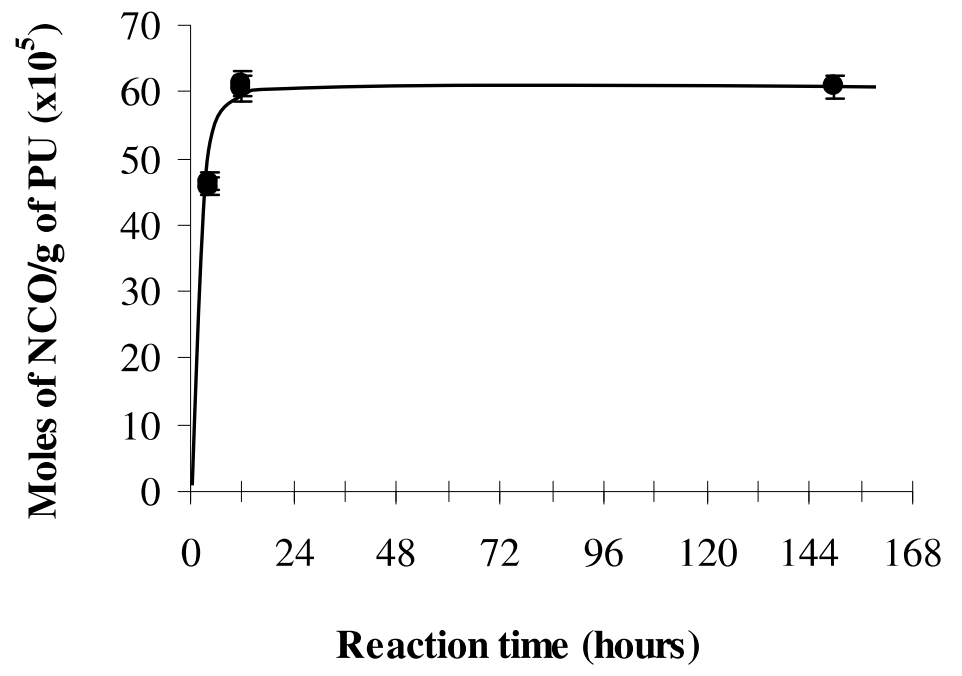

Figure 1. Time dependence of the reaction between NCO and diethyl amine.

\subsection{The reaction between NCO and HEMA and the role of chain extender}

Chemical incorporation of HEMA in the PU prepolymer chains is an important reaction step as the amount of HEMA further determines the number of connecting points between the acrylic and PU chains and the cross-linking density of the network after chain extension with BPA. Scheme 1 shows the PU/HEMA coupling reaction and subsequent chain extension reactions of PU or HEMA-functionalized PU with BPA. Besides these main reactions, undesirable side reactions can also take place. For instance, the PU prepolymer can also undergo chain extension with water during the emulsification step or in the course of polymerization. This results in the formation of an unstable carbamic acid that evolves into a primary amine that can subsequently react with $\mathrm{NCO}$ to form an urea. This side reaction primarily occurs at the hybrid particle/water interface, and is undesirable as it would tend to locate the PU prepolymer near the particle surface and promote bridging flocculation. ${ }^{32,35}$ Moreover it is responsible for a loss of stoichiometry, as for each reacting water molecule, two NCO groups are consumed, which would lead to shorter PU chains. The isocyanate may also react with acrylic acid, releasing carbon dioxide and forming an amide. ${ }^{56}$ However, this reaction is not favoured as isocyanates 
should react more quickly with alcohols or with the $\mathrm{OH}$ group of water than with $\mathrm{COOH}$ groups. $^{56}$

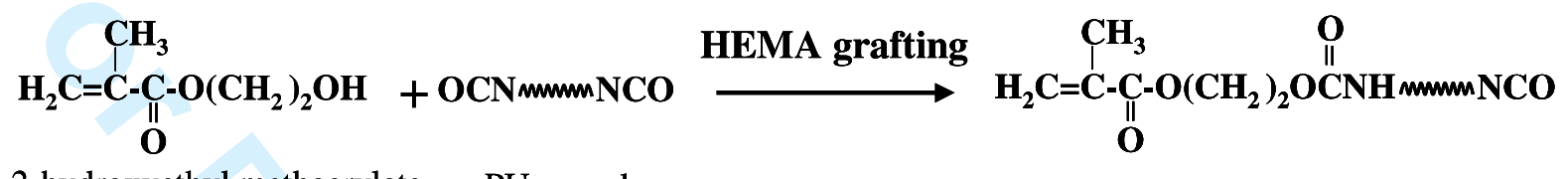

2-hydroxyethyl methacrylate PU prepolymer

(HEMA)

HEMA-functionalized PU prepolymer

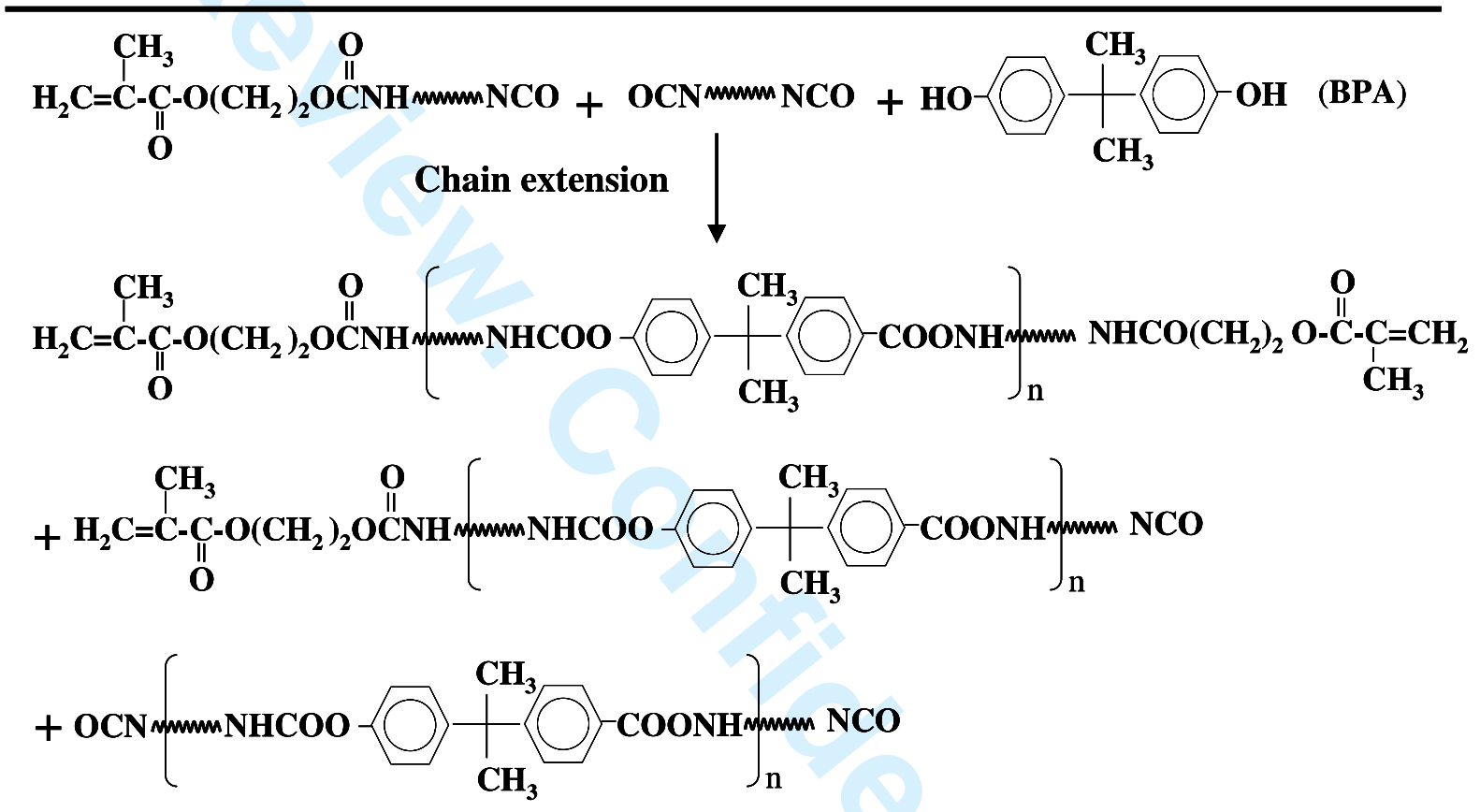

Scheme 1: Schematic representation of HEMA grafting to PU and all possible subsequent reactions between PU or HEMA-functionalized PU and BPA.

The chain-extended PU prepolymer containing HEMA functionalities on one end or on both ends can then react in situ with the acrylic radicals during polymerization leading to a hybrid PU/acrylic network composed of dangling PU chains and cross-linked polyacrylic chains as schematically represented below. The proportion of both types of chains depends on the stoichiometry of the polyaddition reaction (e.g. the $\mathrm{OH} / \mathrm{NCO}$ ratio) which in turns depends on the amount of BPA for a fixed HEMA content. Further cross-linking may also result from occasional chain transfer of the propagating radicals to the PU or the acrylic 
copolymer and subsequent coupling reaction of the grafted polymer chains. For the sake of clarity, these last two reactions have not been represented in Scheme 2.

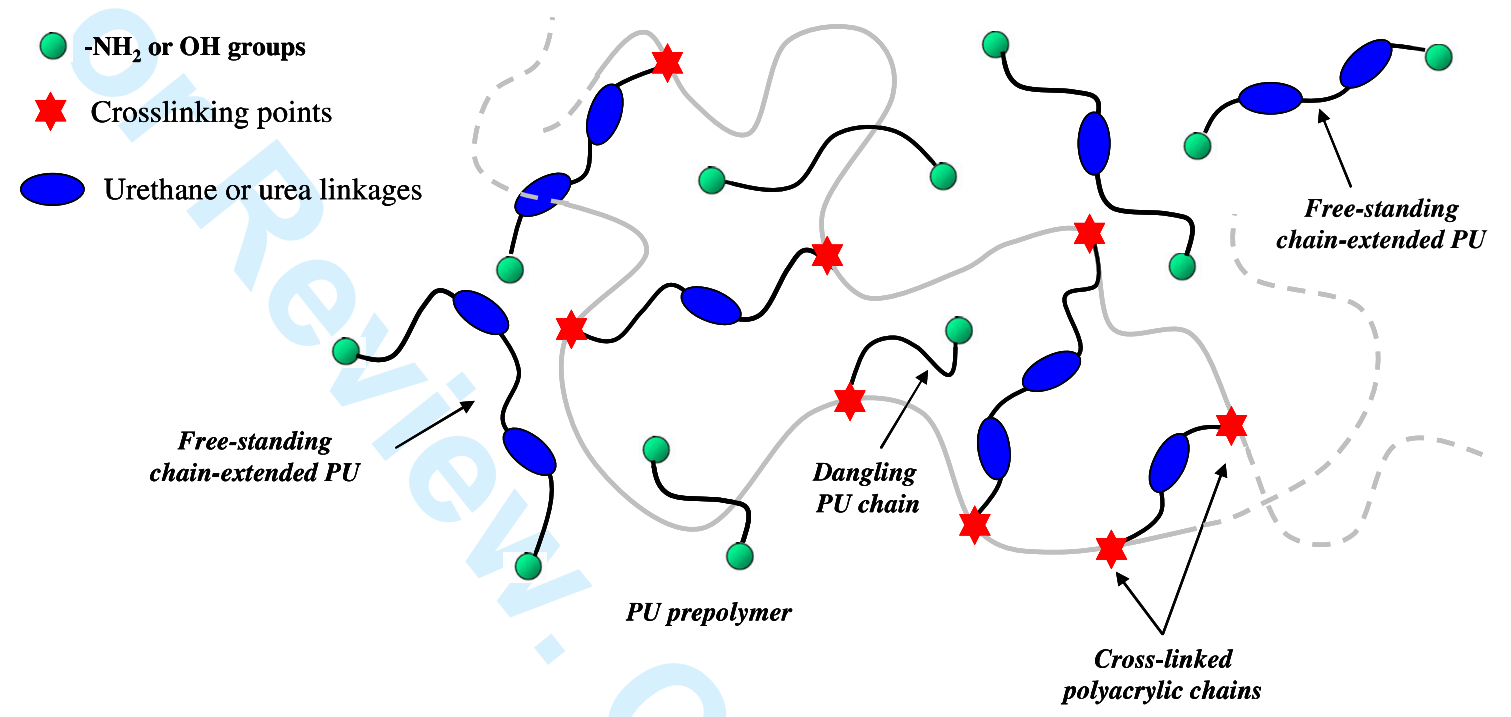

Scheme 2. Schematic representation of the structure of the PU/polyacrylic hybrid network.

The main performances of waterborne PSA materials such as tack, peel adhesion and shear strength (cohesion) are to a large extent governed by the structure of the polymer network and the film morphology. ${ }^{47-49}$ Therefore, it is essential to control both the level of chain transfer to the polymer during the acrylic polymerization, the chemical reaction between HEMA and PU and the chain extension process which all contribute to modify the gel and sol fraction and the molecular weight between cross-linking points in the gel. Regarding the morphology, in the present paper, we do not really discuss the possible phase separation between the PU and the acrylic phases. This question will be addressed in a forthcoming paper combining transmission electron microscopy and additional mechanical analysis.

The conductimetric method described above for NCO titration was used to determine the yield of the reaction between NCO and HEMA by measuring the amount of residual NCO groups. Figure 2 shows the evolution of the grafting yield, and of the grafted amount (expressed as the mol percent of HEMA grafted with respect to the total number of NCO 
groups) with increasing relative HEMA contents for a fixed reaction period of twelve hours and a fixed reaction temperature of $25^{\circ} \mathrm{C}$ using dibutyltin dilaurate as catalyst.

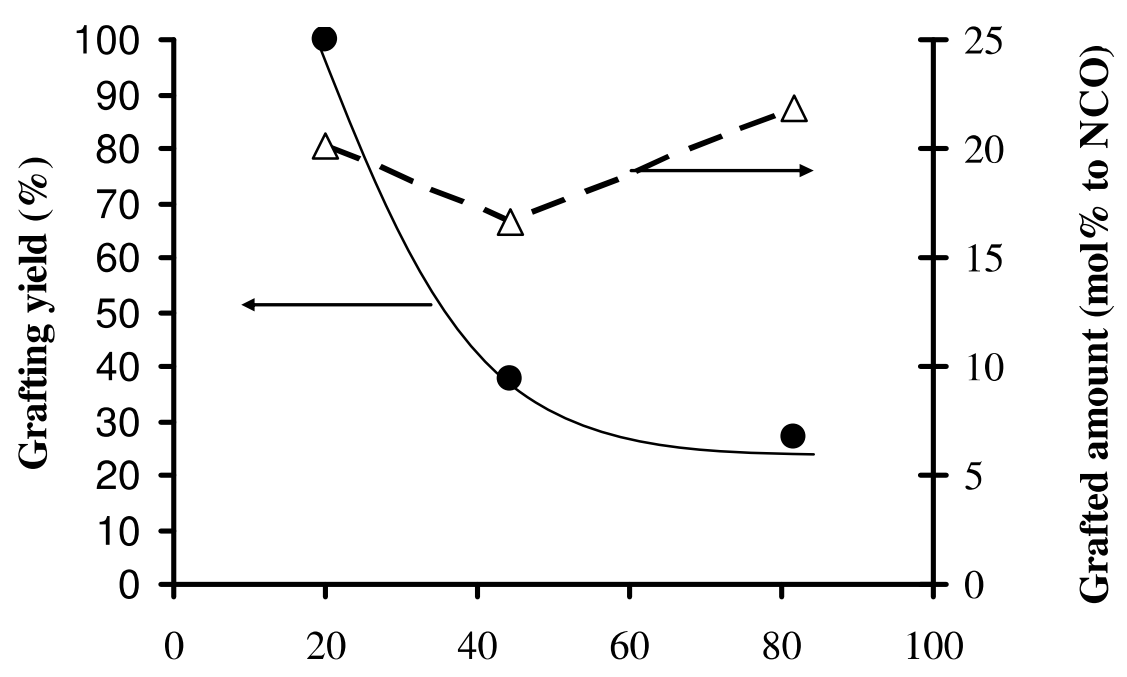

[HEMA] (mol\% to NCO)

Figure 2. HEMA grafting yield and grafted amount as a function of HEMA content.

It can be seen that $100 \%$ HEMA is incorporated in the PU chains for molar contents lower than typically $20 \%$ (based on the amount of NCO groups) which corresponds to $1.6 \mathrm{wt} \%$ HEMA based on PU. The grafting yield then decreases with increasing HEMA quantity. The low grafting yield is likely related to the low reactivity of NCO groups towards HEMA. Indeed, the reaction rate between di-isocyanates and alcohols is known to be much lower than that between isocyanates and amines. Therefore, it is concluded that under the chosen experimental conditions, the maximum molar amount of HEMA that can be introduced in the PU chains, while maintaining 100\% grafting yield, is $20 \%$. Accordingly, the HEMA content could be varied from 0 to $20 \mathrm{~mol} \%$ based on $\mathrm{NCO}$, and the remaining isocyanate groups were neutralized with BPA.

In terms of properties, the desired role played by the chain extender is to increase the average molecular of the PU bridges between acrylic chains. However the choice of the specific diol used as a chain extender can have important effects on the process. ${ }^{57}$ In all 
cases, the chain extender helps to consume the residual NCO groups, which minimizes the potential side reaction between NCO and water mentioned above. Different types of chain extenders (hydrophilic and hydrophobic) have been described in the literature for the purpose of chain extension of urethane prepolymers. ${ }^{32}$ However, it has been shown that when hydrophilic chain extenders are used, the chain extension reaction primarily occurs at the interface between the latex particles and the aqueous phase. ${ }^{32}$ As a result, the urethane moiety tends to be pulled towards the interface which increases the likelihood that the hybrid latex particles aggregate by bridging flocculation, resulting in extensive flocculation. In contrast, when a hydrophobic chain extender is used, chain extension takes place inside the latex particles, and flocculation can in principle be prevented. Therefore, in the following, BPA was used as a hydrophobic chain extender.

Moreover, to facilitate the miniemulsification process and form small droplets, the chain extension reaction was performed in situ during polymerization. The effect of chain extension on droplet size and latex stability is discussed below.

\section{Chain extension with BPA, miniemulsification and polymerization of the miniemulsion}

During a first series of experiments, $25 \mathrm{wt} \%$ of PU with respect to monomers was incorporated into the organic phase. The choice of $25 \% \mathrm{PU}$ is an arbitrary starting point, representative of the range of values (0-50\%) that we will examine below. A redox system (TBHP/SFS) was used in these experiments to increase the reaction rate and prevent side reactions between the remaining NCO groups and water. Indeed, it has been shown that the reaction between NCO and BPA is time-dependent even though it is catalyzed by dibutyltin dilaurate. ${ }^{32}$ According to Li et al. ${ }^{32}$ in the absence of catalyst, only $84 \%$ yield is achieved after a time period of 74 hours while in the presence of a reasonable amount of catalyst $(0.125 \mathrm{mM})$, the reaction takes about 24 hours to reach completion. This reaction time remains rather long so that the addition of a calculated amount of BPA does not necessarily mean that all free $\mathrm{NCO}$ functions are protected from the reaction with water. 
The side reaction of $\mathrm{NCO}$ with water was evident in the observed decrease of the initial droplet size by about $20 \mathrm{~nm}$ after aging the miniemulsion for 20 minutes which approximately corresponds to the time before we start the polymerization (Table 2). Li et $a l .{ }^{32}$ has also shown that about $20 \%$ of NCO functions are lost during a time period of $2 \mathrm{~h}$. Similar observations were also reported by Barrere and Landfester during the synthesis of aqueous PU dispersions in miniemulsion. ${ }^{12}$ Why this constant decrease in droplet size should occur is not clear. It is possible that given the reaction between the NCO and the water leading to the formation of hydrophilic amine end groups, the prepolymer is "pulled" to the interface and this causes a reorganisation of the internal structure of the droplets. However, regardless of the reason for this slight change, in the following, the droplet size measured just before initiation was considered for the calculation of $\mathrm{N}_{\mathrm{d}}$.

Table 2. Variation of droplet diameter during the time period between sonication and initiation of polymerization.

\begin{tabular}{lllll}
\hline Samples & T143 & T144 & T145 & T146 \\
\hline Droplet diameter just after sonication $(\mathrm{nm})$ & 136 & 138 & 140 & 139 \\
Droplet diameter just before initiation $(\mathrm{nm})$ & 119 & 120 & 123 & 126 \\
\hline
\end{tabular}

To minimize potential side reactions of $\mathrm{NCO}$ with water, one alternative solution is to rapidly polymerize the acrylic monomers and perform the polymerization at low temperature to decrease the water solubility inside the particles. For instance, it has been shown that the use of a redox pair of initiators instead of KPS could help minimizing the isocyanate/water reaction in a hybrid system based on reactive PU. ${ }^{32}$ As a matter of fact, when KPS was used as initiator at $70^{\circ} \mathrm{C}$ (instead of $40^{\circ} \mathrm{C}$ for the redox pair), the latex was unstable and flocculated within a few minutes. Unfortunately, in the present work, unstable latexes were also obtained in the presence of a redox initiator even though we used a stoichiometric amount of BPA. We speculate that flocculation occurs because BPA is situated close to the droplet/water interface where chain extension can further takes place. The reason for BPA being situated near the interface is that the droplets (and thus 
particles) are very hydrophobic given the quantity of PU and ODA that they contain. It is possible that this leads to a segregation of material in the droplet with the less hydrophobic BPA being "pushed" toward the interface. Instability may be additionally promoted by the high solids content $(50 \%)$ and the small size $(130 \mathrm{~nm}$ diameter) of the latex particles leading to low inter-particle distances. Therefore, in the following, only half a stoichiometric amount of BPA was used for the chain extension process (e.g., $\mathrm{OH} / \mathrm{NCO}=0.55)$ to ensure the formation of stable latexes. We will discuss this point in detail in section 3 below (modifications and formulation improvement).

The two initiators were then compared to identify the system that yielded the best balance of properties. Table 3 shows the solids content and gel content of two blank experiments performed in the absence of PU using KPS (T28) and the redox initiator pair (T107), respectively.

Table 3. Main characteristics of control samples synthesized using KPS (T28) and a redox pair (T107) as initiators.

\begin{tabular}{lcc}
\hline Samples & T28 & T107 \\
\hline PU $(\mathrm{wt} \%)^{\mathrm{a}}$ & 0 & 0 \\
Droplet diameter $(\mathrm{nm})$ & 103.7 & 78.8 \\
Final particle diameter $(\mathrm{nm})$ & 131.4 & 95.8 \\
$\mathrm{~N}_{\mathrm{p}} / \mathrm{N}_{\mathrm{d}}$ of final latex & 0.39 & 0.47 \\
Monomer conversion $(\%)$ & 100 & 100 \\
Solids content $(\mathrm{wt} \%)$ & 42 & 42 \\
Gel content $(\mathrm{wt} \%)^{\mathrm{b}}$ & 72 & 84 \\
\hline
\end{tabular}

${ }^{\mathrm{a}}$ Based on monomers. ${ }^{\mathrm{b}}$ Determined using equation (1)

It is seen that the gel content is lower for the KPS- than for the redox-initiated latex sample (Table 3). This is likely due to the difference of reaction temperature and different reactivity of the propagating radicals. Indeed, it has been reported that oxygen-centered radicals are more efficient than carbon-centered radical to abstract hydrogen and lead therefore to more gel formation. ${ }^{58}$ 
The adhesive properties of the films were characterized using a well-established probetack test. ${ }^{52-53}$ The adhesion energy, that is to say the energy required to debond the probe from the sample, is a fast and easy criterion that can be combined with the failure type to analyze the adhesive properties. A good permanent PSA must have high adhesion energy and detach with an interfacial failure between the adhesive and the substrate. We can see in Figure 3 that the adhesion energy of the redox sample is lower than that of the KPS sample, while an interfacial debonding mode is observed between the adhesive film and the probe. This lower adhesion energy and the force-displacement curves reveal that the adhesive prepared using the redox initiator deforms less before detaching, indicating a higher level of crosslinking in agreement with the gel measurements.

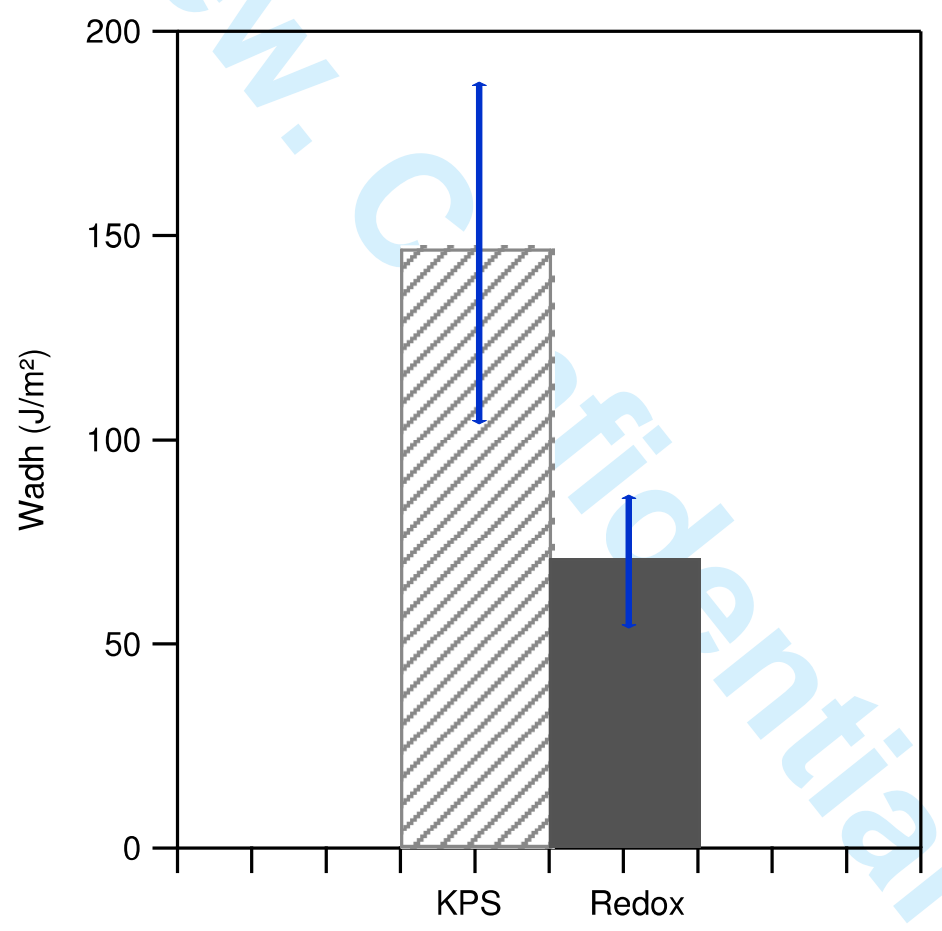

Figure 3. Adhesion energies obtained with the probe-tack test for samples elaborated using two different initiators. The controlled debonding velocity is $10 \mu \mathrm{m} . \mathrm{s}^{-1}$.

In the following, in order to lower the gel content while using a redox system, a small amount of chain transfer agent (CTA) was introduced in the recipe. The amount of CTA was varied from 0 to $0.3 \mathrm{wt} \%$ with respect to monomers. The characteristics of the 
resulting latexes are summarized in Table 4 while Figure 4 displays the evolutions of the monomer conversion and of $\mathrm{N}_{\mathrm{p}} / \mathrm{N}_{\mathrm{d}}$ with time for this series of experiments.

Table 4. Main characteristics of the hybrid miniemulsions and hybrid latexes elaborated in the presence of increasing amounts of CTA and fixed PU and HEMA contents. $\mathrm{OH} / \mathrm{NCO}=0.55$.

\begin{tabular}{|c|c|c|c|c|c|}
\hline Samples & T107 & $\mathrm{T} 144$ & $\mathrm{~T} 143$ & $\mathrm{~T} 145$ & T146 \\
\hline $\mathrm{PU}(\mathrm{wt} \%)^{\mathrm{a}}$ & 0 & 25 & 25 & 25 & 25 \\
\hline CTA $(w t \%)^{\mathrm{a}}$ & 0 & 0 & 0.1 & 0.2 & 0.3 \\
\hline HEMA (mol\% to NCO) & l & 10 & 10 & 10 & 10 \\
\hline Droplet diameter (nm) & 78.8 & 120 & 119.1 & 122.8 & 126.1 \\
\hline Final particle diameter $(\mathrm{nm})$ & 95.8 & 119.9 & 118 & 121.4 & 115.8 \\
\hline $\mathrm{N}_{\mathrm{p}} / \mathrm{N}_{\mathrm{d}}$ of final latex & 0.47 & 0.88 & 0.90 & 0.91 & 1.1 \\
\hline Monomer conversion (\%) & 100 & 100 & 99.9 & 100 & 99.4 \\
\hline Solids content (wt\%) & 42 & 49.8 & 49.8 & 49.8 & 49.8 \\
\hline Gel content $(w t \%)^{b}$ & 84 & 84 & 65 & 44.5 & 23.6 \\
\hline
\end{tabular}

${ }^{a}$ Based on monomers. ${ }^{b}$ Determined using equation (1). ODA: $5.15 \mathrm{wt} \%^{\mathrm{a}}$

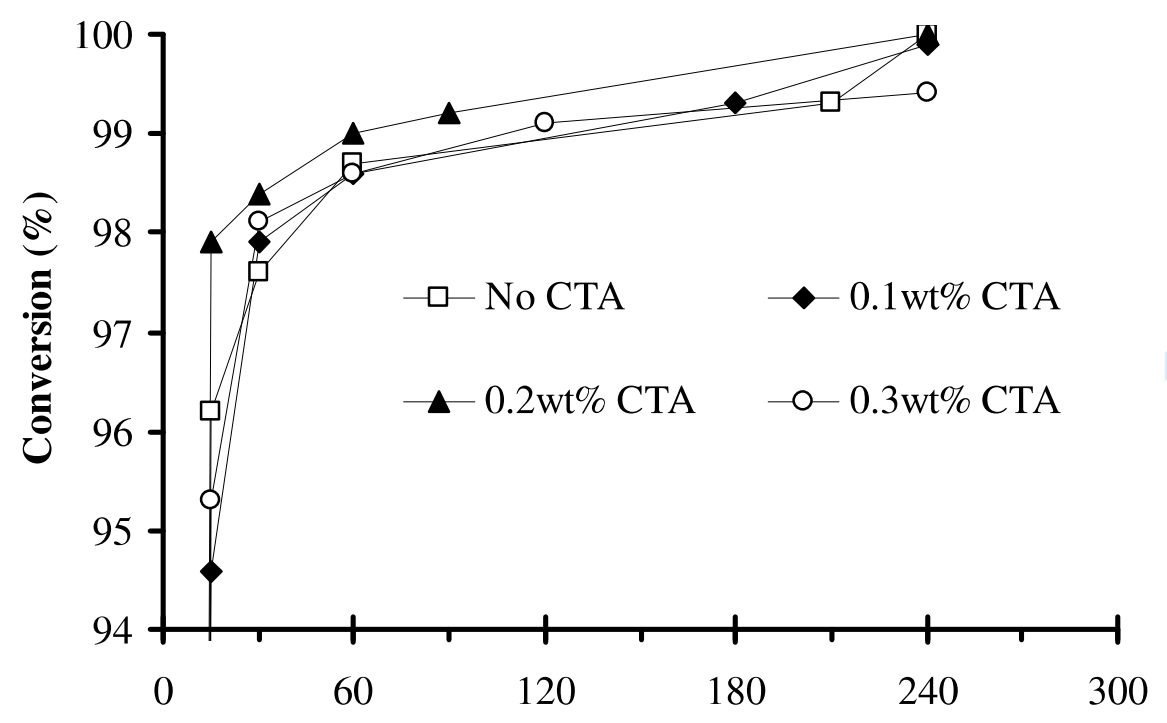

Time (minutes) 


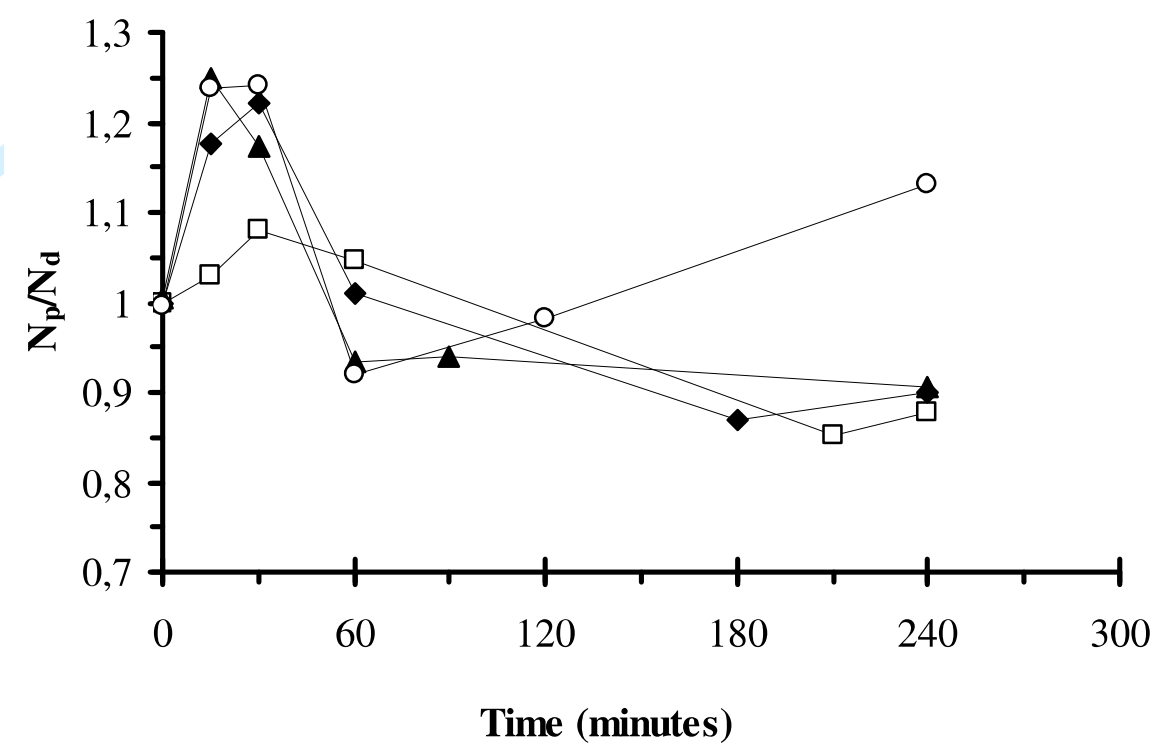

Figure 4. Evolution of monomer conversion (a) and of $\mathrm{N}_{\mathrm{p}} / \mathrm{N}_{\mathrm{d}}$ (b) with time for a series of miniemulsion polymerizations performed with increasing amounts of CTA.

First, it is worth mentioning that all of the final latexes were colloidally stable and did not exhibit any significant increase in particle size over a time period of several months. As shown in Table 4 and Figure 4, the polymerization reaction was very fast and complete monomer conversion could be achieved in less than 3 hours in any case while maintaining a good control of $\mathrm{N}_{\mathrm{p}} / \mathrm{N}_{\mathrm{d}}$ which was comprised between 0.85 and 1.25. A closer examination of the evolution of $\mathrm{N}_{\mathrm{p}} / \mathrm{N}_{\mathrm{d}}$ with time (Figure $4 \mathrm{~b}$ ) shows that $\mathrm{N}_{\mathrm{p}} / \mathrm{N}_{\mathrm{d}}$ slightly increased after 30 minutes of polymerization (i.e., the particle size decreased) and then decreased by the end of polymerization. The main mechanism that can lead to a decrease in particle size in the present system is via the formation of new particles during the course of the reaction by secondary nucleation. Secondary nucleation is promoted by the presence of monomer in the aqueous phase. Some of this monomer will be due to the partitioning of MMA between the two phases. It is possible that as polymer accumulates in the particles, the solubility conditions that were present at the beginning of the reaction change in such a way (i.e. the particles cannot absorb all the monomer they originally contained) that MMA partitions more toward the water. In addition, the $\mathrm{NCO} /$ water side reaction is expected to 
form PU chains with hydrophilic amine end groups. Perhaps these hydrophilic PU chains contribute to the release of surfactant from the surface of the original droplets, thereby promoting the stabilization of the smaller particles formed by secondary nucleation. The following increase of particle size indicates some particle coalescence that can be tentatively ascribed to chain extension of the PU prepolymer that may further take place due to the presence of residual NCO groups that can react with the amine-end-capped PU. Note that all reactions occurred within a very short period of time as almost $90 \%$ conversion was obtained after only 1 hour. This means that further chemical reactions of the NCO groups of PU with BPA (if any) or with water can take place after polymerization. We will discuss this point in detail in section 3 .

Figure 5 represents the adhesion energies for this series of experiments. As expected, we can see that the CTA content has a strong effect on the adhesive properties. ${ }^{47} 0.2 \mathrm{wt} \%$ of CTA gives a higher adhesive energy combined with an adhesive failure. This corresponds to higher permanent adhesion. As seen in Table 3, the gel content decreases with increasing the amount of CTA as might be expected. Therefore, it can be concluded that a balanced level of cross-linking is obtained for $0.2 \mathrm{wt} \%$ of CTA which was the amount used in further experiments.

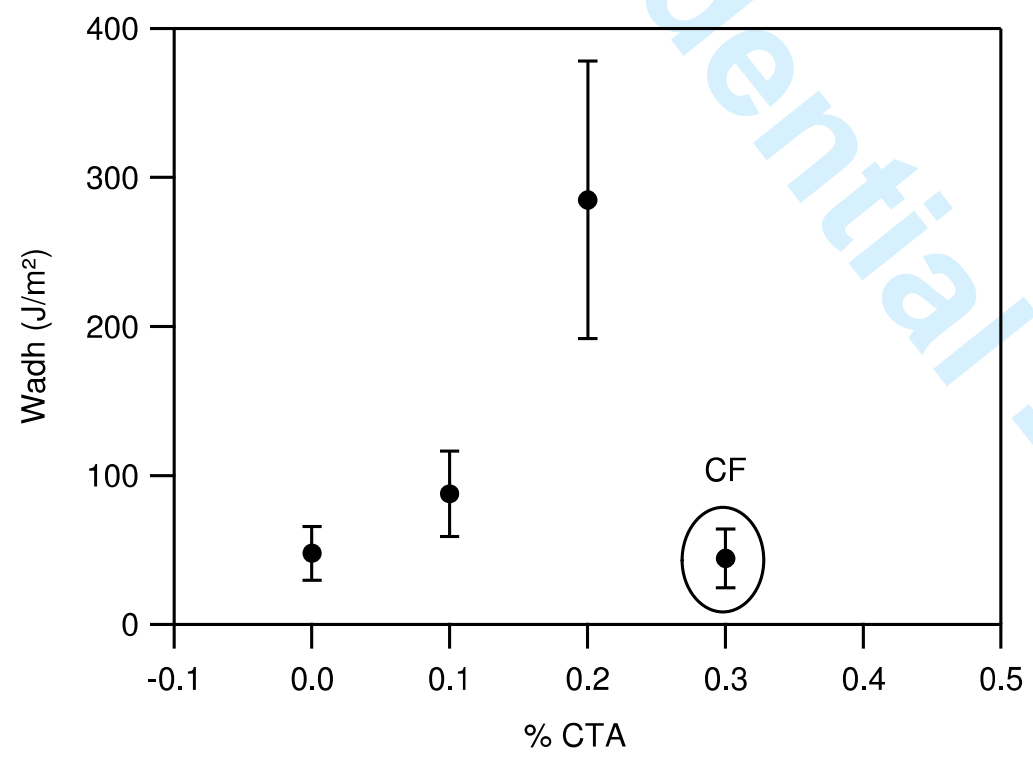


Figure 5. Adhesive surface energy of hybrid latexes elaborated in the presence of increasing amounts of CTA. PU $=25 \mathrm{wt} \%, \mathrm{ODA}=5.5 \mathrm{wt} \%, \mathrm{HEMA}=10 \mathrm{~mol} \%$ and $\mathrm{OH} / \mathrm{NCO}=0.55$. Debonding velocity $\mathrm{V}_{\mathrm{deb}}=100 \mu \mathrm{m} . \mathrm{s}^{-1}$. CF is for cohesive failure.

Having determined an appropriate level of CTA and an $\mathrm{OH} / \mathrm{NCO}$ ratio leading to stable latexes and balanced tack properties, we performed a new series of experiments to find out the best levels of HEMA for $25 \mathrm{wt} \%$ PU and $0.2 \mathrm{wt} \%$ of CTA. The amount of grafted HEMA was varied from 5 to $20 \mathrm{~mol} \%$ based on the total amount of NCO groups (Table 5).

Table 5. Main characteristics of the hybrid miniemulsions and hybrid latexes elaborated in the presence of increasing HEMA contents and fixed PU and CTA contents.

\begin{tabular}{|c|c|c|c|c|c|}
\hline Samples & 8 & $\mathrm{~T} 147$ & $\mathrm{~T} 145$ & T148 & T149 \\
\hline $\mathrm{PU}(\mathrm{wt} \%)^{\mathrm{a}}$ & & 25 & 25 & 25 & 25 \\
\hline CTA $(w t \%)^{\mathrm{a}}$ & & 0.2 & 0.2 & 0.2 & 0.2 \\
\hline HEMA (mol\% to NCO) & & 5 & 10 & 15 & 20 \\
\hline Droplet diameter (nm) & & 121.8 & 122.8 & 123.6 & 123.6 \\
\hline Final particle diameter (nm) & & 129.4 & 121.4 & 131.1 & 128.2 \\
\hline $\mathrm{N}_{\mathrm{p}} / \mathrm{N}_{\mathrm{d}}$ of final latex & & 0.73 & 0.91 & 0.73 & 0.78 \\
\hline Monomer conversion $(\%)$ & & 100 & 100 & 100 & 100 \\
\hline Solids content (wt\%) & & 49.8 & 49.8 & 49.8 & 49.8 \\
\hline Gel content $(w t \%)^{b}$ & & 31 & 44.5 & 47.2 & 58.4 \\
\hline
\end{tabular}

${ }^{\mathrm{a}}$ Based on monomers. ${ }^{\mathrm{b}}$ Determined using equation (1). ODA: $5.15 \mathrm{wt} \%{ }^{\mathrm{a}}$

As before for CTA, the HEMA content has no obvious influence on the droplet diameter and on the final particle size. Again, the polymerizations were very fast and reached $96 \%$ conversion in 30 minutes and full conversion in $2 \mathrm{~h}$ with a good control of $\mathrm{N}_{\mathrm{p}} / \mathrm{N}_{\mathrm{d}}$.

The gel content increased gradually with increasing HEMA content. Since the quantity of CTA was constant, the increase of gel content with increasing the amount of HEMA is likely due to the increased amount of incorporated PU and the corresponding increased density of PU bridges in the hybrid network. Probe tack experiments (Figure 6) reveal that $5 \%$ NCO grafting by HEMA results in a cohesive failure of the adhesive (insufficient 
crosslinking) while $10 \%$ grafting gives a higher adhesion energy than 15 or $20 \%{ }^{51}$ This again reflects that an optimal density of PU bridges to maximize the adhesion energy while avoiding cohesive failure is achieved in these conditions. So the remainder of the experiments focused on this range of values.

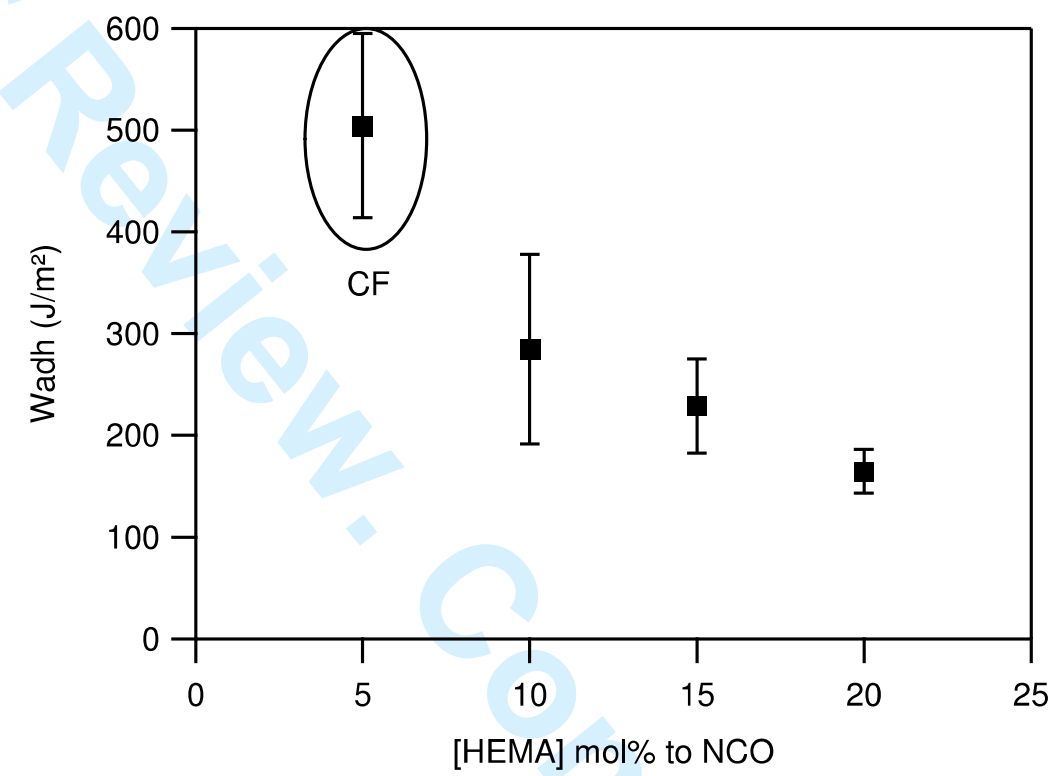

Figure 6. Adhesive surface energy of hybrid latexes elaborated with different amounts of HEMA. $\mathrm{PU}=25 \mathrm{wt} \%, \mathrm{ODA}=5.5 \mathrm{wt} \%, \mathrm{CTA}=0.2 \%$ and $\mathrm{OH} / \mathrm{NCO}=0.55 ;$ Debonding velocity $\mathrm{V}_{\mathrm{deb}}=100 \mu \mathrm{m} \cdot \mathrm{s}^{-1}$. CF is for cohesive failure.

Subsequently, fixing CTA at $0.2 \mathrm{wt} \%$ and HEMA at $10 \mathrm{~mol} \%$ grafting, we varied the PU content from 5 to $50 \mathrm{wt} \%$. Table 6 shows the evolution of the droplet size, $\mathrm{N}_{\mathrm{p}} / \mathrm{N}_{\mathrm{d}}$ and the gel content for this series of experiments. As expected, the droplet size increases with increasing PU content. This is suspected to be due to the increasing viscosity of the monomer/PU solution. Similar observations were made by Wang et al. during the synthesis of acrylic/PU hybrid latexes by miniemulsion polymerization. ${ }^{33,34}$ On the other hand, $\mathrm{N}_{\mathrm{p}} / \mathrm{N}_{\mathrm{d}}$ increased from 0.5 to 1.3 with increasing PU content. It is possible that the PU plays the role of a co-stabilizer and provides extra stability to the miniemulsion droplets, preventing them from coalescing (e.g. $\mathrm{N}_{\mathrm{p}} / \mathrm{N}_{\mathrm{d}}$ is closer to 1). Indeed, several authors have reported that $\mathrm{PU}$ is an efficient co-stabilizer in miniemulsion 
polymerization. ${ }^{30-31}$ At last, it is seen that the gel content also increases with the amount of PU which is clear indication that PU plays the role of cross-linker in the system.

Table 6. Main characteristics of the hybrid miniemulsions and hybrid latexes elaborated in the presence of increasing amounts of PU and fixed CTA and HEMA contents.

\begin{tabular}{|c|c|c|c|c|c|}
\hline Samples & $\mathrm{T} 150$ & T151 & $\mathrm{T} 145$ & $\mathrm{~T} 152$ & T153 \\
\hline $\mathrm{PU}(\mathrm{wt} \%)^{\mathrm{a}}$ & 5 & 15 & 25 & 35 & 50 \\
\hline CTA $(w t \%)^{\mathrm{a}}$ & 0.2 & 0.2 & 0.2 & 0.2 & 0.2 \\
\hline HEMA (mol\% to NCO) & 10 & 10 & 10 & 10 & 10 \\
\hline Droplet diameter (nm) & 80.1 & 104 & 122.8 & 135.5 & 148.7 \\
\hline Final particle diameter $(\mathrm{nm})$ & 93.6 & 105.9 & 121.4 & 130.5 & 131.9 \\
\hline $\mathrm{N}_{\mathrm{p}} / \mathrm{N}_{\mathrm{d}}$ of final latex & 0.54 & 0.82 & 0.91 & 0.99 & 1.3 \\
\hline Monomer conversion $(\%)$ & 100 & 100 & 100 & 100 & 100 \\
\hline Solids content (wt\%) & 45.5 & 47.7 & 49.8 & 49.9 & 49.9 \\
\hline Gel content $(\mathrm{wt} \%)^{\mathrm{b}}$ & 9 & 29.1 & 44.5 & 58.2 & 73.8 \\
\hline Mode of debonding & cohesive & cohesive & adhesive & adhesive & adhesive \\
\hline Maximum Extensibility & 20.0 & 20.0 & 13.9 & 3.7 & 1.3 \\
\hline Adhesion Energy $\left(\mathrm{J} / \mathrm{m}^{2}\right)$ & $\begin{array}{c}161.2 \pm \\
43.2\end{array}$ & $\begin{array}{c}379.3 \pm \\
111.3\end{array}$ & $\begin{array}{c}284.9 \pm \\
93.3\end{array}$ & $\begin{array}{c}143.6 \pm \\
39.9\end{array}$ & $\begin{array}{c}49.6 \pm \\
5.2\end{array}$ \\
\hline
\end{tabular}

${ }^{\mathrm{a}}$ Based on monomers. ${ }^{\mathrm{b}}$ Determined using equation (1). ODA: $5.15 \mathrm{wt} \%{ }^{\mathrm{a}}$

Probe-tack experiments performed on this series of latexes showed that the highest adhesion energy combined with interfacial debonding is obtained for PU levels of $25 \mathrm{wt} \%$. It should be noted that a full factorial design might have led to slightly different "optimal" levels, but this rapid screening allowed us to identify reasonable starting conditions in a short period of time. These starting conditions were further improved as reported below.

\section{Modifications and formulation improvements}

As described above, the objective in using BPA is that of a controlled PU chain extension through the reaction between free NCO functions and BPA, which would lead in the 
absence of side reactions and for a fixed $\mathrm{OH} / \mathrm{NCO}$ stoichiometry, to an increase in the molecular weight of the PU and to a decrease in the density of PU bridges. In other words, being able to vary the levels of BPA will give us an additional parameter for the control of the network architecture of the gel fraction, which in turns is essential to control properties.

Yet the use of a stoichiometric amount of BPA following the recipe of Table 1, led to the flocculation of the system during the latter stages of polymerization. A possible reason for this instability is the bridging flocculation which takes place at the hybrid particle-water interface. The difference in hydrophilicity between the BPA on the one hand, and the acrylic monomer plus ODA plus mercaptan on the other hand might lead to droplets which are not spatially homogeneous in terms of the concentration of the different constituents. Thus the BPA might be preferentially located at the surface of the droplets because of the presence of its $\mathrm{OH}$ groups, so it is reasonable to assume that hydrophobic chain extension mainly took place at the droplet/water interface. This scenario would promote bridging flocculation. Hence, it was expected that removing ODA would contribute to a reduction of the formation of floc in the presence of a stoichiometric amount of BPA.

In order to verify this assumption, the following experiment was carried out. A recipe of a previous successful run was used (T145 - half a stoichiometric amount of BPA) but without ODA and with a stoichiometric amount of BPA. All the experimental conditions were similar except the mentioned changes. The characteristics of the corresponding hybrid miniemulsions and latexes are shown in Table 7. No flocculation occurred during this synthesis leading us to believe that the above assumption is correct.

Figure 7 shows the particle size variation of the two latexes (T145-50\% BPA and T159full amount of BPA) with time after polymerization. The increase of particle size compared to the initial particle size just after the synthesis is likely due to the reaction of free NCO functions with water and this confirms that this side reaction is faster than the catalysed reaction of BPA and NCO. However BPA competes with water molecules and hence the increase of particle size is controlled when a stoichiometric amount of BPA is 
used. To conclude, increasing the amount of BPA while removing ODA led to an improvement in the colloidal stability of the hybrid latex suspension.

Table 7. Main characteristics of the hybrid miniemulsions and hybrid latexes elaborated in the presence of a half stoichiometric (T145) and a stoichiometric (T159) amount of BPA based on the total number of residual NCO groups.

\begin{tabular}{|c|c|c|}
\hline 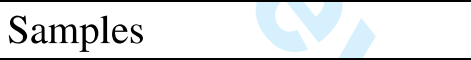 & $\mathrm{T} 145$ & T159 \\
\hline $\mathrm{PU}(\mathrm{wt} \%)^{\mathrm{a}}$ & 25 & 25 \\
\hline CTA $(w t \%)^{\mathrm{a}}$ & 0.2 & 0.2 \\
\hline ODA $(\mathrm{wt} \%)^{\mathrm{a}}$ & 5.15 & 0 \\
\hline HEMA (mol\% to NCO) & 10 & 10 \\
\hline $\mathrm{BPA}(\mathrm{mol} \%$ to $\mathrm{NCO})$ & 45 & 90 \\
\hline $\mathrm{OH} / \mathrm{NCO}$ & 0.55 & 1 \\
\hline Droplet diameter (nm) & 122.8 & 115.3 \\
\hline Final particle diameter $(\mathrm{nm})$ & 121.4 & 120.7 \\
\hline $\mathrm{N}_{\mathrm{p}} / \mathrm{N}_{\mathrm{d}}$ of final latex & 0.91 & 0.76 \\
\hline Monomer conversion (\%) & 100 & 100 \\
\hline Solids content (wt\%) & 49.8 & 49 \\
\hline Gel Content $(w t \%)^{b}$ & 44.5 & 48.5 \\
\hline Mode of debonding & adhesive & adhesive \\
\hline Maximum Extensibility & 13.9 & 11.7 \\
\hline Adhesion Energy $\left(\mathrm{J} / \mathrm{m}^{2}\right)$ & 284.9 & 249.3 \\
\hline
\end{tabular}

${ }^{\mathrm{a}}$ Based on monomers. ${ }^{\mathrm{b}}$ Determined using equation (1) 


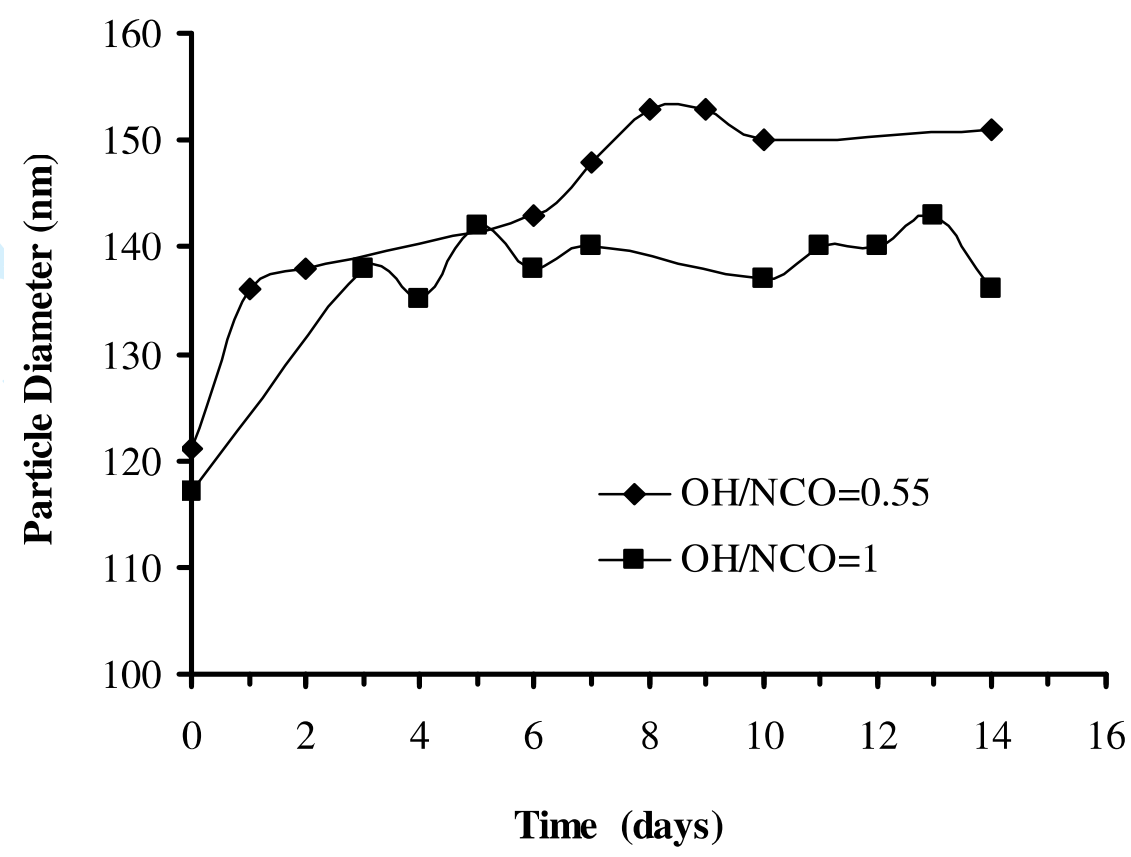

Figure 7. Effect of the amount of BPA on the evolution of the final particle size with time after polymerization. Particle diameters are determined with an accuracy of $+/-5 \mathrm{~nm}$.

Apart from the change in the average particle size and latex colloidal stability, the removal of ODA and the increased proportion of BPA in the initial formulation had some effects on the polymer network architecture inside each particle. These changes in network architecture cannot be easily characterized directly by a spectroscopic technique but have important effects on the mechanical and adhesive properties.

When comparing T145 and T159, it appears that the gel content increased slightly and the maximum deformability of the adhesive was lower for T159 $(\mathrm{OH} / \mathrm{NCO}=1)$ than for T145 $(\mathrm{OH} / \mathrm{NCO}=0.55)$ resulting in a $12 \%$ decrease in adhesion energy. This result points to the formation of more PU bridges between the acrylic chains and is unexpected since the BPA should have acted as a chain extender, i.e., at fixed HEMA content should have had no effect on the density of PU bridges. However for this series, the amount of HEMA is low and probably T145 still contained many dangling PU chains, which are then connected into bridges when additional BPA is available (as in T159). 
To fine tune the adhesive properties and increase the adhesion energy while using a stoichiometric amount of BPA and no ODA, we can use two synthetic tools: increasing the CTA concentration will reduce the acrylic kinetic chain length and the gel content could be significantly lowered increasing deformability, while increasing the amount of HEMA can increase the degree of grafting and hence crosslink the gel with tighter mesh and decrease deformability. Although in principle both tools act similarly on the deformability of the adhesive, they are not equivalent.

A new series of experiments was then performed by first varying the amount of CTA alone and then varying it while concurrently the amount of HEMA was increased to $20 \%$. The characteristics of the resulting latexes and films are summarized in Table $8 . \mathrm{N}_{\mathrm{P}} / \mathrm{N}_{\mathrm{d}}$ varied in a manner very similar to Figure $4 \mathrm{~b}$ and once again, we obtained complete monomer conversions. The mechanical and adhesive properties were then tested and some conclusions could be drawn from the results of the probe tests. The sample T160 was simply a version of T159 with $0.3 \%$ CTA instead of $0.2 \%$. This change led to a cohesive failure of the adhesive, i.e. an insufficient number of PU bridges. However when the amount of HEMA was increased from 10 to $20 \mathrm{~mol} \%$, an optimum deformability of the adhesive before debonding without cohesive failure was found for a CTA content of $0.3 \%$.

Table 8. Main characteristics of the hybrid miniemulsions and hybrid latexes elaborated using a stoichiometric amount of BPA in the presence of increasing amounts of CTA.

\begin{tabular}{|c|c|c|c|c|c|}
\hline Samples & T160 & $\mathrm{T} 161$ & T162 & T163 & T164 \\
\hline $\mathrm{PU}(\mathrm{wt} \%)^{\mathrm{a}}$ & 25 & 25 & 25 & 25 & 25 \\
\hline CTA $(w t \%)^{\mathrm{a}}$ & 0.3 & 0.2 & 0.25 & 0.3 & 0.4 \\
\hline HEMA (mol\% to NCO) & 10 & 20 & 20 & 20 & 20 \\
\hline Droplet diameter (nm) & 120 & 121.2 & 118.5 & 121 & 115.1 \\
\hline Final particle diameter $(\mathrm{nm})$ & 143.5 & 119.8 & 118.6 & 123 & 115.4 \\
\hline $\mathrm{N}_{\mathrm{p}} / \mathrm{N}_{\mathrm{d}}$ of final latex & 0.51 & 0.91 & 0.87 & 0.83 & 0.87 \\
\hline Monomer conversion (\%) & 100 & 100 & 100 & 100 & 100 \\
\hline Solids content (w\%) & 49.1 & 49.1 & 50 & 49.9 & 49.1 \\
\hline Gel content $(w t \%)^{b}$ & 38.5 & 57.5 & 52.5 & 44.6 & 43.6 \\
\hline Mode of debonding & Cohesive & Adhesive & Adhesive & Adhesive & Cohesive \\
\hline Maximum Extensibility & $\infty$ & 7.7 & 10 & 19 & $\infty$ \\
\hline Adhesion Energy $\left(\mathrm{J} / \mathrm{m}^{2}\right)$ & NA & 271 & 362 & 438 & NA \\
\hline
\end{tabular}


${ }^{a}$ Based on monomers. ${ }^{b}$ Determined using equation (1).

Finally it may be interesting to compare two samples with identical amounts of CTA but with $\mathrm{OH} / \mathrm{NCO}=0.55$ (with ODA) and $\mathrm{OH} / \mathrm{NCO}=1$ (without ODA) in the high degree of grafting limit. The two samples are T149 and T161 and their characteristics are shown on Table 9. Both T149 and T161 detach adhesively from the probe but the deformability upon failure of the T149 sample and hence its adhesion energy is much lower. In this high grafting regime, the additional BPA acts as expected, i.e. as a chain extender of PU, reducing therefore the deformability of the adhesive film. It should be noted however that the gel contents similar for the two samples (58.4\% for the sample with ODA and $57.5 \%$ for the sample without) whereas the macroscopic properties are not. This suggests that we did indeed modify the level of crosslinking of the gel fraction by changing the PU molar mass through chain extension with BPA while leaving the sol fraction unaffected. This change in polymer architecture would not have been possible with a change in kinetic chain length of the acrylic.

Table 9. Main characteristics of the hybrid latexes elaborated using a half stoichiometric (T149) and a stoichiometric (T161) amount of BPA for 20mol\% HEMA grafting.

\begin{tabular}{lcc}
\hline Samples & T 149 & T 161 \\
\hline PU (wt \%) $)^{\mathrm{a}}$ & 25 & 25 \\
CTA (wt\%) & 0.2 & 0.2 \\
HEMA (mol\% to NCO) & 20 & 20 \\
BPA (mol\% to NCO) & 45 & 90 \\
OH/NCO & 0.55 & 1 \\
Gel content (wt\%) & 58.4 & 57.5 \\
Mode of debonding & Adhesive & Adhesive \\
Maximum Extensibility & 4.4 & 7.7 \\
Adhesion Energy $\left(\mathrm{J} / \mathrm{m}^{2}\right.$ ) & 164 & 271 \\
\hline${ }^{\mathrm{a}}$ Based on monomers. ${ }^{\mathrm{b}}$ Determined using equation $(1)$.
\end{tabular}




\section{Conclusion}

High solids content hybrid latexes incorporating a reactive PU prepolymer have been successfully synthesized by polymerization of miniemulsion droplets. The degree of grafting of the reactive PU to the copolymer chains was controlled by the incorporation of a known amount of double bonds by reacting HEMA with PU in a separate step. This amount was determined quantitatively and the residual NCO groups were next reacted with BPA. Then, miniemulsions were successfully polymerized and the PSA properties of films of the resulting latexes were tested. The results of the tests allowed us to identify the key parameters to change in the formulation of the miniemulsion droplets in order to optimize the PSA properties of the resulting latexes in terms of deformability while avoiding cohesive failure. The amount of CTA, the degree of grafting of NCO by HEMA (hence different ratios of HEMA/BPA) and different amounts of PU were altered in the formulations. In general a good control of $\mathrm{N}_{\mathrm{p}} / \mathrm{N}_{\mathrm{d}}$ could be obtained for all of these experiments and complete monomer conversions could be achieved in each case. The best adhesive properties were obtained either with $0.2 \mathrm{wt} \%$ CTA, 25wt $\%$ PU and $10 \%$ NCO grafting by HEMA in the presence of a half stoichiometric amount of BPA with respect to NCO or with $0.3 \%$ CTA, $25 \mathrm{wt} \%$ PU and $20 \%$ NCO grafting by HEMA in the presence of a stoichiometric amount of BPA with respect to NCO. In both cases, respectable values of adhesion energies of the order of $400 \mathrm{~J} / \mathrm{m}^{2}$ were obtained in probe tack corresponding to peel forces of the order of $4 \mathrm{~N} / \mathrm{cm}$.

\section{Acknowledgment}

The authors are grateful for funding provided by the European Commission's Sixth Framework Programme though the NAPOLEON Project (Contract number IP 011844-2).

\section{Supporting Information Available}

SEC and FTIR analyses of the reactive PU prepolymer. This information is available free of charge via the Internet at http://pubs.acs.org/. 


\section{References}

1. Seymour, R. B.; Kauffman, G. B. J. Chem. Educ. 1992, 69, 909-910.

2. Szycher's Handbook of Polyurethanes, Szycher, M. CRC Press, Boca Raton (1999)

3. Meier-Westhues, U. In Polyurethanes: Coatings, Adhesives and Sealants. Vincentz Network GmbH \& Co (European Coating Tech Files), Hannover, Germany (2007).

4. Kim, B. K.; Lee, Y. M. J. Macromol. Sci. Pure Appl. Chem. 1992, 29, 1207-1221.

5. Klein, H.-P.; Schawb, M. Polym. Paint Colour J. 1994, 184, 444-446.

6. Lee, J. S.; Kim, B. K. Prog. Org. Coat. 1995, 25, 311-318.

7. Cheong, I. W.; Nomura, M.; Kim, J. H. Macromol. Chem. Phys. 2000, 201, 22212227.

8. Dieterich, D. Prog. Org. Coat. 1981, 9, 281-340.

9. Rosthauser, J. W.; Nachtkamp, K. Advances in Urethane Science and Technology 1987, 10, 121-162.

10. Tharanikkarasu, K.; Kim, B. K. Progress in Rubber and Plastics Technology 1997, $13,26-55$.

11. Li, C. Y.; Chiu, W. Y.; Don, T. M. J. Polym. Sci., Part A: Polym. Chem. 2005, 43, 4870-4881.

12. Barrère, M.; Landfester, K. Macromolecules 2003, 36, 5119-5125.

13. Lin, M.; Chu, F.; Guyot, A.; Putaux, J-L.; Bourgeat-Lami, E. Polymer 2005, 46, 1331-1337.

14. Guyot, A.; Landfester, K.; Schork, F. J.; Wang, C. Prog. Polym. Sci. 2007, 32, 14391461.

15. Okamoto, Y.; Hasegawa, Y.; Yoshino, F. Prog. Org. Coat. 1996, 29, 175-182.

16. Kim, B. Y.; Lee, J. C. J. Appl. Polym. Sci. 1995, 58, 1117-1124.

17. Hegedus, C. R.; Kloiber, K. A. J. Coatings Technol. 1996, 68, 39-48.

18. Kim, J. Y.; Suh, K. D. Coll. Polym. Sci. 1996, 274, 920-927.

19. Hirose, M.; Kadowaki, F.; Zhou, J. Prog. Org. Coat. 1997, 31, 157-169.

20. Kukanja, D.; Golob, J.; Valant, A. Z.; Krajnc, M. J. Appl. Polym. Sci. 2000, 78, 6780. 
21. Zhang, H. T.; Guan, R.; Yin, Z. H.; Lin, L. L. J. Appl. Polym. Sci. 2001, 82, 941947.

22. Kukanja, D.; Golob, J.; Krajnc, M. J. Appl. Polym. Sci. 2002, 82, 941.

23. Zhang, G.; Zhang, Z.; Hu, Z.; Xi, H. Colloids and Surfaces A: Physicochem. Eng. Aspects 2005, 264, 37-42.

24. Lu, Y.; Larock, R. C. Biomacromolecules 2007, 8, 3108-3114.

25. Chai, S. L.; Jin, M. M.; Tan, H. M. Eur. Polym. J. 2008, 44, 3306-3313.

26. Jeon, H. T.; Lee, S. K.; Kim, B. K. The Journal of Adhesion 2008, 84, 1-14.

27. Chai, S. L.; Jin, M. M. J. Appl. Polym. Sci. 2009, 114, 2030-2035.

28. Athawale, V. D.; Kulkarni, M. A. Prog. Org. Coat. 2009, 65, 392-400.

29. Peruzzo, P. J.; Anbinder, P. S.; Pardini, O. R.; Costa, C. A.; Leite, C. A.; Galembeck, F.; Amalvy, J. I. J. Appl. Polym. Sci. 2010, 116, 2694-2705.

30. Gooch, J. W.; Dong, H.; Schork, F. J. J. Appl. Polym. Sci. 2000, 76, 105-114.

31. Wang, C.; Chu, F.; Graillat, C.; Guyot, A. Polym. React. Eng. 2003, 11, 541-562.

32. Li, M.; Daniels, E. S.; Dimonie, V.; Sudol, E. D.; El-Aasser, M. S.Macromolecules 2005, 38, 4183-4192.

33. Wang, C.; Chu, F.; Graillat, C.; Guyot, A.; Gauthier, C.; Chapel, J-P. Polymer 2005, 46, 1113-1124.

34. Wang, C.; Chu, F.; Graillat, C.; Guyot, A.; Gauthier, C. Polym. Adv. Technol. 2005, $16,139-145$.

35. Wang, C.; Chu, F.; Guyot, A.; Gauthier, C.; Boisson, F. J. Appl. Polym. Sci. 2006, $101,3927-3941$.

36. Wang, C.; Chu, F.; Guyot, A. J. Disp. Sci. Technol. 2006, 27, 325-330.

37. Wang, S.; Zhang, G.; Zhang, Z.; Zou, M. Colloids and Surfaces A: Physicochem. Eng. Aspects 2007, 298, 158-162.

38. Wang, C.; Chu, F.; Jin, L.; Lin, M.; Xu, Y.; Guyot, A. Polym. Adv. Technol. 2009, 20, 319-326.

39. Wang, H.; Wang, M.; Ge, X. Radiation Physics and Chemistry 2009, 78, 112-118.

40. Schork, F. J.; Poehlein, G. W.; Wang, S.; Reimers, J.; Rodrigues, J.; Samer, C. Colloids and Surfaces A: Physiochem. Eng. Aspects 1999, 153, 39-45.

41. Asua, J. M. Prog. Polym. Sci. 2002, 27, 1283-1346. 
42. Antonietti, M.; Landfester, K. Prog. Polym. Sci. 2002, 27, 689-757.

43. Lopez, A.; Chemtob, A.; Milton, J. L.; Manea, M.; Paulis, M.; Barandiaran, M. J.; Theisinger, S.; Landfester, K.; Hergeth, W. D.; Udagama, R. McKenna, T. F. L.; Simal, F.; Asua, J. M. Industrial \& Engineering Chemistry Research 2008, 47, 62896297.

44. a) Ouzineb, K.; Lesauze, N.; Graillat, C.; McKenna, T. F. L. Chem. Eng. Sci. 2006, 61, 2994-3000. b) El-Jaby, U.; Cunningham, M.; McKenna, T. F. L. AIChE J. DOI: $10.1002 /$ aic.12365.

45. Farzi, A.; Bourgeat-Lami, E.; McKenna, T. F. L. J. Appl. Polym. Sci. 2009, 114, $3875-3881$.

46. Sood, A.; Awasthi, S. K. J. Appl. Polym. Sci. 2003, 88, 3058-3065.

47. Gower, M. D.; Shanks, R. A. Macromolecular Chemistry and Physics 2004, 205, 2139-2150.

48. Jovanovic, R.; Dubé, M. A. J. Macromolecular Sci. Part C: Polymer Reviews 2004, $44,1-51$.

49. a) Tobing, S. D.; Klein, A. Journal of Applied Polymer Science 2001, 79, 22302244. b) Tobing, S. D.; Klein, A. Journal of Applied Polymer Science 2001, 79, 2558-2564.

50. Deplace, F.; Carelli, C.; Mariot, S.; Retsos, H.; Chateauminois, A.; Ouzineb, K.; Creton, C. Journal of Adhesion 2009, 85, 18-54.

51. Degrandi-Contraires, E.; Udagama, R.; Bourgeat-Lami, E.; McKenna, T. F. L.; Ouzineb, K.; Dupont, O.; Creton, C. Submitted to Macromolecules

52. Zosel, A. J. Adhes. 1989, 30, 135-149.

53. Lakrout, H.; Sergot, P.; Creton, C. J. Adhes. 1999, 69, 307-359.

54. David, D. J.; Staley, H. B. In: Analytical Chemistry of Polyurethane, Wiley Interscience, New York, pp. 86-90 (1969).

55. Shi, Y.; Zhan, X.; Luo, Z.; Zhang, Q.; Chen, F. J. Polym. Sci., Part A: Polym. Chem. 2008, 46, 2433-2444.

56. Yoon, J.; Lovell, P. A. Macromolecular Chemistry and Physics 2008, 209, 279-289.

57. Lopez, A. E. Design and Production of Waterborne Polyurethane/Acrylic Hybrid Pressure Sensitive Adhesives. PhD Thesis. University of the Basque Country, 2010. 
58. Ilundain, P.; Alvarez, D.; Da Cunha, L.; Salazar, R.; Barandarian, M. J.; Asua, J. M. J. Polym. Sci. Part A: Polym. Chem. 2003, 41, 3744-3749. 


\section{For Table of Contents Use Only}

Synthesis of Acrylic-Polyurethane Hybrid Latexes by Miniemulsion Polymerization and their Pressure-Sensitive Adhesive Applications

Ravindra Udagama, ${ }^{1}$ Elise Degrandi-Contraires ${ }^{2}$ Costantino Creton, ${ }^{2}$ Christian Graillat, ${ }^{1}$ Timothy F.L. McKenna, ${ }^{1}$ Elodie Bourgeat-Lami ${ }^{*}$

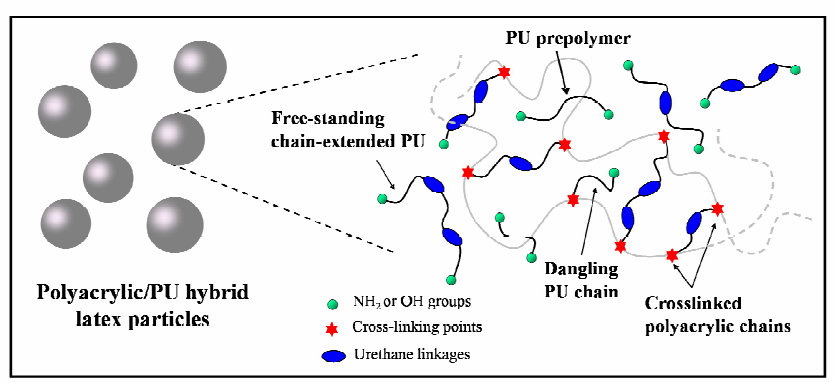

